\title{
THE ADOPTION OF SOME COUNSELLING TECHNIQUES IN TEACHING PRACTICE SUPERVISION
}

\author{
BY \\ OSAGIE OBAZEE G. E. \\ School of Education \\ College of Education, Ekiadolor Benin \\ and \\ OBASEKI F. N. \\ School of Education \\ College of Education, Ekiadolor Benin
}

\begin{abstract}
The trend in primary and secondary education, as specified by the national educational objectives of the federal government of Nigeria, is to have a balanced education; education embracing the cognitive, affective and the psychomotor. For too long, teachers have been trained well to handle the cognitive domain of education and to some degree the psychomotor is given to them in the affective area. In this regard counsellors can make some contributions. One such contribution is where counselling techniques can be adopted in teaching practice supervision. Thus, this paper describes three techniques such as acceptance, feedback modelling and how they can be used profitably in teaching practice supervision.
\end{abstract}

Key words; counselling techniques, teaching practice, supervision.

\section{Introduction}

Counselling is basically a process in which a counsellor either assist one individual to explore his personal issues or problems and to find solutions to them. Egbochuku (2009 cited Egbochuku 2002) defined 
counselling as a "face to face" situation in which a counsellor, by virtue of her training and skills, helps the client to face, perceive, clarify, solve and resolve his adjustment problems/issues the counselling process is thus a relationship because it involves interaction between the counsellor and the counsellee or an interaction in a group where the counsellor is an expert. It is a helping relationship the outcome of which is self-growth for the counsellee. The self-growth may be realized in the form of a new awareness of an aspect of one's behaviour or a concrete change from an undesirable one.

Teaching practice supervision on the other hand is a process in which the supervisor helps, guides or direct a student teacher in his teaching to enable him enrich his professional skills and also grow as a person. Asaya (2004) defined teaching practice supervision as a process of helping, directing and guiding the activities of teachers in training so as to facilitate their professional growth, it is aimed at assessing the teaching effectiveness of student-teacher for the purpose of grading him for certification. It is a helping relationship just as counselling is and involves an interaction between the supervisor and the student teacher.

The student teacher is obliged to undergo the teaching practice process, be observed, and have interactions with the supervisor, unlike in counselling where the client voluntarily enter into the process. This mark a major difference between the two processes. The focus of the national educational objectives outlined in the national policy on education (2004) is on the three domains, the cognitive, affective and psychomotor domains, but emphasis is more on the cognitive domain. One implication of this is that teachers will have to be trained to improve on their skills in the affective and psychomotor domain, teacher in training need adequate training in the affective area to enable them facilitate the personality growth of their pupils. One way to help in such training is to adopt counselling techniques in teaching practice supervision since such techniques deals with the personality matters of people. Three counselling techniques described in this paper that can be extensively and deliberately use in teaching practice supervision are: acceptance, feedback and modelling.

Three counselling techniques and their application to teaching practice supervision.

Acceptance

Acceptance is recognizing or accepting an individual with a positive regard, treating him as a worthwhile person. Corey, (1990) is of the view 
that acceptance is a means of respect for an individual without discrimination. In other words acceptance implies an unconditional regard and care for an individual's person no matter what his personality attributes are, acceptance is demonstrated through listening attentively with understanding and communicating warmth and liking to other person. It is important that these responses are expressed genuinely for the other person to perceive them as genuine. When they are not, the individual perceives the relationship with doubts and withholds expressing himself freely and genuinely.

Acceptance does not imply approval of everything the other persons does; it concerns the worth of the individual as a person and not necessarily his behaviour. (Kolo 1997). We can disapprove of an individual's behaviour and yet communicate to him that we have regard, care and respect for his person. In counselling, the counsellor's acceptance of his counsellee is important for creating a warm, nonthreatening welcoming atmosphere. This means, that the counsellor listens, responds genuinely and shows warmth and likeness. This make the counsellee perceive the counsellor as someone who genuinely respects and cares for him/her. With such perception he/she feels relaxed and safe to express himself/herself freely.

Acceptance in teaching practice supervision means that the supervisor develops a non-threatening relationship with his student teacher, communicate warmth and likeness and genuinely demonstrates interest in helping him/her. These responses must be perceived as genuine by the students through their interactions with the supervisor. Student teacher often time tend to view teaching practice supervision more as an evaluative exercise on his performance than as an exercise which can help him/her to improve his/her professional skills and thus grow, as such some student teachers feel highly anxious and nervous during classroom observation and conference discussions. The supervisors good interpersonal relation with his student teacher to a large extent can reduce this anxiety.

Also acceptance during the conference session is important, it releases the student teacher and makes him/her feel safe and free to take part in the discussions. It makes the student teacher more likely to accept and elaborate on his/her deficiency pointed out by the supervisor.

\section{Feedback}

Giving information about your perception, or reaction to the behaviour of another person is giving the person feedback. Feedback includes selfdisclosure and sometimes we discover that feedback can be a form of 
confrontation, it can be a source of support as well as challenges and guidance. Feedback according to Nwadinigwe (1999) can be:

(1) Confirmatory; affording the individual the opportunity to know when he is on course.

(2) Corrective: this is making the individual who have veered away from course realizing this, by providing them with the information which will enable them achieve success.

(3) Motivating: suggestions for improvement are provided and analyzing the consequences that may follow in case of failure. When a counsellee is not motivated to improve, whatever feedback given becomes meaningless. But when feedback is given as a corrective measure with all sincerity of purpose, the client often accepts it as quite rewarding. Feedback can be constructive or destructive. Destructive feedback is not meant to help another person but to hurt or belittle him. It is given in a blunt judgment way with focus on the person instead of the behaviour of the person. This is given disregarding how it affects the person receiving it. Constructive feedback on the other hand, aims at helping and not hurting or belittling. It is given in a nonthreatening way so as to make the receiver decrease his defenses. It describes the behaviour instead of judging it. It focuses on the behaviour of the receiver and describes what is observed and not inference with the observations. For example, "you speak so softly in class that about half of the class at the back do not hear what you say". In constructive feedback, the language used, the tone the voice and even the posture and the facial expression of the giver is such as to make the receiver perceive the good intention of the giver and accept, examine and explore further the information given.

Feedback is used in teaching practice supervision a great deal so it features prominently in conference sessions as the supervisor gives and discusses information about his observation of how a student teacher handled a class. The feedback thus comprises of observation, information on strength and weakness of the student teacher's teaching behaviour. It provides data for his weakness, examination, exploration and discussion of means of employing his strength more productively and also improving on his deficiencies. One strategy the supervisor can adopt is to discuss feedback on the strength of a student before discussing his 
weakness, thus may help to reduce the anxiety level of highly anxious student teachers.

Feedback on the strength of a student teacher is very important, it can make him aware of some strength he may have no knowledge of, it is also reinforcing just to hear that one can do such and such so well.

\section{Modelling}

Modelling is a process of learning whereby a person (the model) exhibits a behaviour which serves as an example for another person (the observer) or reproduce or imitate because the learners observe the behaviour before reproducing it. (Ingule, Rono and Ndumbuki 1996) limitation is influenced by how the model is affected by the consequences of his behaviour. Bandura, Ross and Ross (1963 as cited in Gesinde 1991) asserted that if the model is rewarded for his behaviour, it is more likely that the observer will imitate the model's behaviour, if punished, the observer is less likely to imitate him. Reinforcing the observer while he is observing a model tends to increase the probability that he will reproduce the model's behaviour.

Observational learning can occur in counselling process in two ways; firstly, when the counsellee imitates a counsellor's behaviour, which the counsellor has not meant to serve as a model. Secondly when the counsellor and the counsellee deliberately and systematically utilize modelling to shape certain skills or responses of the counsellee. In the first case the counsellee may pick certain responses of the counsellor, like how he sits, how he pronounces certain words, his accepting and supportive responses, how he reinforces and gives feedback. When this happens, it means the counsellee had grown to like and to identify with the counsellor.

The second case is utilized by behaviour counsellors through their deliberate use of models to help counsellee pick up certain skills or responses, the counsellor can use himself or another adult as a live model to demonstrate certain specific responses or he can utilize the counselle's peers in a small group situation (group counselling) to do the same thing. The use of symbolic models such as films, audio, video tapes, computers etc can be employed in modelling certain skills to the counsellee. Modelling techniques is often time used by the counsellor to help counsellee overcome phobias (unreasonable fear) to acquire desired responses and to inhibit undesirable ones.

The use of modelling to help teachers is very relevant in teaching practice supervision. The supervisor serves as a model to his student's teachers. Some of the responses he exhibits during conference sessions 
can serve as appropriate behaviour models. For example during the course of discussion he may show acceptance, reinforce the positive teaching responses of a student teacher, confront him constructively. All these and other responses he may express, if properly exhibited can be appropriate behaviour models a student teacher may imitate and use in his teaching.

One deliberate way of utilizing modelling techniques to help student's teachers is through discussion of procedures they can adopt to solve some specific "teaching problems" in their classroom. A method once demonstrated, discussed and used successfully serves as an example for solving similar problems in future. An hypothetical example is given below to illustrate the above point.

A supervisor consults with a student teacher on a boy in JSS 1 who cannot form words out of letter and writes them. All other children in his class can do this and can even form and write simple sentences. This boy seems to have lost confidence to achieve it like other children. The supervisor assists the teacher to map out the following procedures for solving the problems.

i. Defining the problems in behavioural terms e.g. Boy cannot form words out of letters. He cannot write words. He has no interest in learning.

ii. Description of objectives to be achieved by the boy in behavioural terms e.g. after treatment (a) boy to be able to have interest in learning,

iii. Determining reinforcement complementary to the boy e.g. boy likes teachers approval.

iv. Building a friendly relationship with the boy,

v. Developing graded tasks from very easy task gradually to difficult ones (very easy tasks being in the ability level of the child).

vi. Assigning tasks to child-beginning with very easy task and moving up the ladder and reinforcing him when he is correct.

vii. Increasing confidence level of the boy to achieve, through further tasks and reinforcement.

The mapped out method serves as a model to be tried by the teacher and if successful, it can be used in solving similar problems in future. 


\section{Conclusion}

It is a glaring fact that the teaching of affective skills in our schools is not effective, this is because most teachers were not thoroughly equip with the skill during the course of training. The utilization of counselling techniques in teaching practice supervision is one way counselling can contribute in training teachers to acquire positive affective skills. Other ways through which didactic and experimental courses in the affective domain can be taught to students is by getting up special counselling services for student teachers' use in order to improve the personality of the student teachers.

\section{References}

Asaya S. A. (2004) Teaching Practice Handbook for Student Teachers. Lagos JOAEC Publishers.

Corey G. (1990) Theory and Practice of Counselling and Psychotherapy (2nd edition) Montercycal Nigeria: Brooks Co.

Egbochuku E. O. (2009) Counselling Communication skills it Place in the Training Programme of a Counselling Psychologist. Edo Journal of counselling, An official Publication of Edo State Chapter, Counselling Association of Nigeria 1(1) 17-32.

Federal Government of Nigeria (2004). National Policy on Education (Revised) Abuja: NERDC Press.

Gesinde S. A. (1991) Information Collection Techniques in Guidance. Ibadan University of Ibadan.

Ingule F. O., Row R. C. and Ndambuki W. (1996) Educational Psychology. Nairobi English Press.

Kolo F. D. (1997) Conditions, Techniques and Skills for an Effective Counselling Process. JOS: Jofegan Associates.

Nwadinigwe I. P. and Anumonye F. O. (1999) Guidance and Counselling for the Expectational Client: A Descriptive and Developmental Approach. Lagos, Charow and Sons.

Orebanjo M. A. (1989) Aids to Teaching Practice. Ijebu-Ode National Press. 